Service social

\title{
Liste des évaluateurs, années 1984, 1985, 1986
}

Volume 35, numéro 3, 1986

Les jeunes et le travail social

URI : https://id.erudit.org/iderudit/706335ar

DOI : https://doi.org/10.7202/706335ar

Aller au sommaire du numéro

Éditeur(s)

École de service social de l'Université Laval

ISSN

1708-1734 (numérique)

Découvrir la revue

Citer ce document

(1986). Liste des évaluateurs, années 1984, 1985, 1986. Service social, 35(3),

496-496. https://doi.org/10.7202/706335ar d'utilisation que vous pouvez consulter en ligne.

https://apropos.erudit.org/fr/usagers/politique-dutilisation/ 


\section{Liste des lecteurs, années 1984, 1985, 1986}

Selon la procédure en vigueur, chaque article reçu est lu par trois personnes pour fin d'appréciation. La liste qui suit regroupe, par ordre alphabétique, les noms des personnes qui ont accepté d'effectuer cette tâche.

AMPLEMAN, Gisèle
AUCLAIR, René
BARITEAU, Claude
BEAUDET, Micheline
BEAUDOIN, André
BÉDARD, Céline
BÉLANGER, Jean-Pierre
BÉLANGER, Pierrette
BILODEAU, Guy
BOILY, Pierre-Yves
BRISSON-AMYOT, Pierrette
CARRIER, Gaby
CLÉRIN, Roland
CÔTÉ, Christian
DAGENAIS, Huguette
DARVEAU, Lise
DELISLE, Marc-André
DESLAURIERS, Jean-Pierre
DORÉ, Gérald
DOUCET, Laval
DUMAS, Lise
DUPUIS, Denis
FILTEAU, Hélène
FORTIN, Denis
FOURNIER, Pierre
FRÉCHETTE, Marcel
GAUDREAU, Lorraine
GOSSELIN, Jean
GOURGUES, Jules-Henri
HÉBERT, Lise

HOME, Alice

JACOB, André

LACROIX, LuC

LAFOREST, Jacques

LAVOIE, Francine

LECOMTE, Roland

LORD, Roland

MESSIER, Camille

OUELLET, Francine

OUELLET, Hector

PATRY, Michèle

PLAMONDON, Denis

PLANTE, Jacques

POULIN, Martin

REDJEB, Belhassen

RINGUET, Jacques

ROBITAILLE, Denise

ROLAND, Marc

SAINT-JACQUES, Marie-Christine

SANTERRE, Renaud

SÉNÉCHAL, Mariette

SIMARD, Marie

TESSIER, Monique

THIBAULT, Michel

TROTTIER, Germain

VACHON, Jacques

VALLIÈRES, Louise

VILLENEUVE, Paul

ZAY, Nicolas 